\title{
EDITORIAL
}

\section{Legal issues in Neonatologist Performed Echocardiography. The Italian experience}

\author{
Pediatric Research (2020) 87:1140-1142; https://doi.org/10.1038/s41390- \\ 019-0721-0
}

\section{INTRODUCTION}

Neonatologist Performed Echocardiography (NPE) for the haemodynamic assessment of sick infants is increasingly used in Neonatal Intensive Care Units (NICUs) worldwide. Three expert consensus statements are published on this topic so far, ${ }^{1}$ providing recommendations for a structured training program and accreditation in NPE. In Italy, interest in NPE has spread fast over the past years. The Italian Study Group of Neonatal Cardiology (ISGNC), part of the Italian Society of Neonatology (ISN), is currently running NPE courses, excluding hands-on practice, on a regular basis. As ISGNC, we ascertained that there was a large variation in the level of expertise and use of echocardiography.

Taking into account this heterogeneity, the ISGNC made the realization of an accredited structured training programme in NPE a priority, as few other countries have done before. ISGNC decided in agreement with the ISN Board to follow the recommendations for NPE suggested in the European Consensus Statement, endorsed by European Society for Paediatric Research (ESPR) and European Society for Neonatology. ${ }^{2}$ ESPR working group identified training standards that were applicable in Europe. They advocated that training should be conducted by skilled neonatologists, yet emphasized the need for close and solid collaboration with pediatric cardiology services.

\section{ASSESSING THE FEASIBILITY AND THE NEED FOR ACCREDITATION IN ITALY}

We initially discussed the feasibility of implementing the chosen recommendations. We identified the following critical issues: it is not a simple teaching course, and practical training requiring a sound programme must be arranged; close collaboration with the Italian Society of Pediatric Cardiology (ISPC) is crucial, in order to assure a safe practice, to hold constant learning, to improve opportunities, and to build a good and successful team work. We also identified the need to certify the entire process, to guarantee high-quality training. Moreover, legal aspects had to be faced and investigated.

In a meeting with the ISPC Board, we explained our project and invited them to pursue this innovative educational programme. Goals, quality of practice, and patient safety were discussed. ISPC eventually offered its support and favourably welcomed and endorsed this project.

Next, we designed a survey in order to explore the utilization of NPE in clinical practice in the Italian NICUs and to verify the actual need of a formal training process. ${ }^{3}$ The response rate was $77 \%$ (88/114). We ascertained that, although the haemodynamic assessment by echocardiography was widely adopted in $94 \%$ of NICUs, mainly performed by neonatologists, followed by cardiol- ogists or both $(57 \%, 15 \%$, and $28 \%$ respectively), institutional protocols for NPE were lacking and there was a heterogeneous combination of parameters and cut-offs used. More interestingly, only in $63 \%$ of centres the first cardiac ultrasound was a comprehensive study aimed at confirming normal structural anatomy, raising concerns on the safety of the current practice of NPE.

\section{FACING LEGAL ASPECTS}

We then analysed medico-legal liabilities related with the realization of an accredited training in NPE in Italy. Two law firms were consulted: one between those our ISN refers to, and the other between those Italian doctor's trade unions refers to. We posed the following nation-specific questions. Legal opinions are written in italics.

\section{IS A NEONATOLOGIST LEGALLY ALLOWED TO PERFORM ECHOCARDIOGRAPHY?}

Like in other European countries, "there is no legal impediment to the use of ultrasound imaging for physicians, who can legitimately report findings during examination". Specific postgraduate training in cardiology is not required. Conversely, "a postgraduate diploma is imposed onto those professional activities that involve the use/ exposure to particular elements and/or potentially dangerous situations, such as radiations and anaesthetic gases. Hence physicians working in radiodiagnostics, radiotherapy and nuclear medicine, as well as in anaesthesia, are required to have a specific postgraduate training".

\section{CAN A NEONATOLOGIST UNDERTAKE ADDITIONAL CLINICAL ROLES IN DIAGNOSIS AND FOLLOW-UP OF CONGENITAL HEART DISEASE (CHD)?}

According to our survey, in Italy, a considerable number of neonatologists perform echocardiography in critically ill neonates with suspicion of $\mathrm{CHD}$ as a first scan, both in haemodynamically stable and unstable neonates ( $46 \%$ and $36 \%$, respectively). Lack of paediatric cardiology service within the same institution $(37 \%$ of centres) and no availability of an online consultant service would favour this.

It was reported that "there is no legal impediment for physicians to use ultrasound imaging", who can therefore legitimately perform echocardiography. Nonetheless diagnosing CHD requires specific training, other than NPE training. Lawyers have strongly advised that the "NPE training and accreditation program should clearly state that the diagnosis or exclusion of a CHD is beyond the scope of the neonatologist performing echocardiography". Certification and accreditation by the European Association of Cardiovascular Imaging and Association for European Pediatric Cardiology (http://www.escardio.org) could meet, for instance, the needs of those who intend to achieve competency in diagnosing congenital heart defects. 
Table 1. Lawsuits related to point-of-care ultrasonography.

\begin{tabular}{|c|c|c|c|c|c|c|c|}
\hline Study & Nation & Period & Population & $\begin{array}{l}\text { Total } \\
\text { cases }\end{array}$ & \multicolumn{3}{|l|}{ Allegation } \\
\hline Stolz et al. ${ }^{6}$ & USA & 2008-2012 & Adult-Emergency Department (ED) & 5 & 4 & 1 & 0 \\
\hline
\end{tabular}

\section{HOW SHOULD A NEONATOLOGIST REPORT THE FINDINGS OF NPE IN THE MEDICAL DOSSIER?}

Published recommendations on NPE suggest that all scans should be reported using a standardized template and be specifically reported as having been carried out by a neonatologist rather than a cardiologist/sonographer. A standardized template would help the health-care professional to adhere to the current guidelines and good practices accredited by the scientific community.

On this topic, legal counsellors also advised to "always declare and write any specific problems previously encountered during examination. It would be worth stating the limits of your scanning", such as bad acoustic windows or malfunctioning equipment, "and recording the type and adequacy of the equipment used as well as what may need further investigation in the written report".

\section{ARE GUIDELINES MANDATORY FOR A NEONATOLOGIST PERFORMING AN ECHOCARDIOGRAPHY?}

Similarly to other medical-care activities, echocardiography should be performed with due diligence. Due diligence is the standard of care that a reasonable professional is expected to take, which includes compliance with guidelines and good practices.

Recent Italian laws have established that a health-care professional who adheres to guidelines and good practices accredited by the scientific community cannot be charged for slight negligence. ${ }^{4}$ Moreover, a National Guidelines Committee was instituted to supervise and coordinate the elaboration of national guidelines by accredited scientific societies. It could be argued that "National Guidelines, as will be dictated by the Committee, will have particular relevance for outlining hypotheses of liabilities towards healthcare professionals" and in general terms guidelines and recommendations will be taken into account in our country.

On the other hand, the Italian Supreme Court recently claimed that, in the event that such recommendations are inadequate with respect to the best care of a specific patient case, the health-care professional has the duty to refrain from this.

\section{ARE TRAINERS SOMEHOW RESPONSIBLE FOR TRAINEES' PRACTICE?}

"Criminal liability is always personal, which means that only the person who has committed the error that constitutes the offence is liable". Likewise, regarding civil liability, lawyers believe that "Trainers and organizers cannot be held responsible for any damage caused to a patient by a doctor who has followed the course and obtained the certificate".

However, legal counsellors have advised that "course programme and trainers' selection should attentively follow the objectives set by guidelines and recommendations", which are meant to train exclusively on functional assessment. On this particular topic, they suggested that in the programme, as well as in a note on the certificate of attendance, "it is clearly stated that the training is not meant to exclude or diagnose congenital heart disease".

Trainers cannot be responsible for what a trainee does but only for what they teach.

Training programme in NPE requires certification in order to ensure quality assurance and to guarantee fulfilment of requirements established by the European Consensus Statement. Thus we will require the Italian NPE training to be certified ISO (International Organization for Standardization) 9001-2015, compliant with international standards, and to be certified by the ESPR special interest group on NPE.

\section{FINAL COMMENTS}

A review of a major legal database in the USA showed no cases alleging misdiagnosis or failure to interpret point-of-care ultrasound (POCUS). On the contrary, both in paediatrics and adult population, there were cases that alleged a failure to perform POCUS or a failure to perform it in a timely manner. ${ }^{5}$ Those few other studies we retrieved on this topic provided comparable data (Table 1). These preliminary findings would encourage NPE use and training, with the understanding that there is potential for legal risk to clinicians either for use or failure to use this tool.

A legal counsellor's guidance can provide useful information on the legitimacy of performing echocardiography, the implications of scanning in order to exclude or diagnose CHD, and the importance of following guidelines.

Particular attention should be paid to defining and following scopes of training courses and conceiving scan reports. Courses should be designed based on the country's needs and health-care regulations.

A clinician who is scanning for a functional assessment should be equipped to recognize a normal heart as well as to know when to promptly consult a cardiologist. Sound training, maintenance of competence, and active involvement in a continuous educational process are all strongly advised.

\section{ACKNOWLEDGEMENTS}

Legal expenses were met by the Italian Society of Neonatology. We would like to express our thanks for the help provided by Granata Associated Law Firm (Milan), especially Matteo Granata, and Berruti Associated Law Firm (Bologna).

\section{THE ITALIAN STUDY GROUP OF NEONATAL CARDIOLOGY OF} THE ITALIAN SOCIETY OF NEONATOLOGY

Irma Capolupo ${ }^{3}$, Rosa Maria Cerbo ${ }^{4}$, Manuela Condò ${ }^{5}$, luri Corsini ${ }^{6}$, Daniela Doni ${ }^{7}$ Benjamim Ficial ${ }^{8}$, Stefano Fiocchi ${ }^{9}$, Simona La Placa ${ }^{10}$, Katia Rossi ${ }^{11}$, Sabrina Salvadori ${ }^{12}$, and Federico Schena ${ }^{13}$ 
${ }^{3}$ Neonatal Intensive Care Unit, Ospedale Pediatrico Bambino Gesù, Rome, Italy; ${ }^{4}$ Neonatal Intensive Care Unit, Fondazione IRCCS Policlinico San Matteo, Pavia, Italy; ${ }^{5}$ Neonatal Intensive Care Unit, Ospedale A. Manzoni, Lecco, Italy; ${ }^{6}$ Neonatal Intensive Care Unit, Division of Neonatology, Careggi University Hospital of Florence, Florence, Italy; ${ }^{7}$ Neonatal Intensive Care Unit, FMBBM San Gerardo, Monza, Italy; ${ }^{8}$ Neonatal Unit, Azienda Ospedaliera Universitaria Integrata di Verona, Verona, Italy; ${ }^{9}$ Neonatologia e Terapia Intensiva Neonatale, Ospedale Valduce, Como, Italy; ${ }^{10}$ Neonatal Intensive Care Unit, AOUP Giaccone, Palermo, Italy; ${ }^{11}$ Neonatal Intensive Care Unit, Policlinico di Modena, Modena, Italy; ${ }^{12}$ Neonatal Intensive Care Unit, Azienda Ospedaliera-Università di Padova, Padova, Italy and ${ }^{13}$ Neonatal Intensive Care Unit, Fondazione IRCCS Cà Granda Ospedale Maggiore Policlinico di Milano, Milan, Italy

\section{AUTHOR CONTRIBUTIONS}

M.S. designed the study, performed the data collection and interpretation, drafted the manuscript, and approved the final manuscript as submitted. S.P. participated to data collection and made critical revisions to the final manuscript. Both the authors approved the final version.

\section{ADDITIONAL INFORMATION}

Competing interests: The authors declare no competing interests.

Publisher's note Springer Nature remains neutral with regard to jurisdictional claims in published maps and institutional affiliations.
Marilena Savoia ${ }^{1}$ and

Salvatore Porzio ${ }^{2}$ on behalf of the Italian Study Group of Neonatal Cardiology of the Italian Society of Neonatology

${ }^{1}$ Neonatal Intensive Care Unit, Azienda Sanitaria Universitaria Integrata S Maria della Misericordia, Udine, Italy and ${ }^{2}$ Neonatal Unit,

San Michele Clinic, Maddaloni, Caserta, Italy Chair of the Italian Study Group of Neonatal Cardiology:

Marilena Savoia

Correspondence: Marilena Savoia (marilena.savoia@gmail.com)

\section{REFERENCES}

1. Singh, Y. et al. Education, training, and accreditation of Neonatologist Performed Echocardiography in Europe-framework for practice. Pediatr. Res. 84, S13-S17 (2018).

2. de Boode, W. P. et al. Recommendations for neonatologist performed echocardiography in Europe: Consensus Statement endorsed by European Society for Paediatric Research (ESPR) and European Society for Neonatology (ESN). Pediatr. Res. 80, 465-471 (2016).

3. Corsini, I. et al. Neonatologist performed echocardiography (NPE) in the Italian Neonatal Intensive Care Units: a national survey. Ital. J. Pediatr. 45, 131 (2019).

4. The "Balduzzi" law (no. 189, November 8, 2012) and the "Gelli - Bianco" law (no. 24, March 8, 2017).

5. Nguyen, J., Cascione, M. \& Noori, S. Analysis of lawsuits related to point-of-care ultrasonography in neonatology and pediatric subspecialties. J. Perinatol. 36, 784-786 (2016).

6. Stolz, L. et al. A review of lawsuits related to point-of-care emergency ultrasound applications. West J. Emerg. Med. 16, 1-4 (2015).

7. Blaivas, M. \& Pawl, R. Analysis of lawsuits filed against emergency physicians for point-of-care emergency ultrasound examination performance and interpretation over a 20-year period. Am. J. Emerg. Med. 30, 338-341 (2012). 